\title{
Optimal Indices for Testing Parkinsonian Rigidity
}

\author{
Heikki Teräväinen*, Joseph K.C. Tsui, Edwin Mak and Donald B. Calne
}

\begin{abstract}
We assessed parkinsonian rigidity objectively at the wrist to determine the optimal angular velocity and displacement for detecting abnormality. The wrist was moved passively with a torque motor and the average work done for one complete cycle was computed. This objective rigidity score (ORS) was compared with a clinical rigidity score (CRS). ORS was more pronounced at faster movement velocities in parkinsonian patients, whereas in normal subjects there was only a modest increase in the score. Angular velocities of 140 to $190 \mathrm{degrees} / \mathrm{second}$ and displacements of \pm 25 to \pm 30 degrees were most sensitive for detecting parkinsonian rigidity and had good correlation with the CRS.
\end{abstract}

RÉSUMÉ: Indices optimaux pour mesurer la rigidité parkinsonienne Nous avons évalué la rigidité parkinsonienne objectivement au niveau du poignet pour déterminer la vélocité et le déplacement angulaire optimal requis pour détecter une anomalie. Le poignet était mobilisé passivement au moyen d'un couple moteur et le travail moyen accompli pour un cycle complet était estimé. Ce score objectif de la rigidité (SOR) a été comparé avec un score clinique de la rigidité (SCR). Le SOR était plus élevé pour des vélocités plus grande du mouvement chez les parkinsoniens, alors que chez des sujets normaux, il n'y avait qu'une légère augmentation du score. Des vélocités angulaires de 140 à 190 degrés/seconde et des déplacements de 25 à 30 degrés étaient les plus sensibles pour la détection de la rigidité parkinsonienne et avaient une bonne corrélation avec le SCR.

Can. J. Neurol. Sci. 1989; 16:180-183

Parkinsonian rigidity is frequently assessed clinically at the wrist by moving the patient's hand, while the patient attempts to relax. Studies employing objective methods for the evaluation of muscle tone have measured torque or work required during finger, ${ }^{1-4}$ elbow, ${ }^{4-15}$ ankle, ${ }^{15-16}$ knee, ${ }^{6.17-18}$ or wrist ${ }^{19}$ movement in various diseases including arthritis, $1-2.4$ muscle diseases, 5 spasticity, 5-7, 14-19 and parkinsonism. 8 -13, 15-16 Objective measurement of wrist rigidity has the obvious advantage of obtaining an unbiased and a more finely graded rigidity value than that based on clinical numerical scores. Various clinical scoring systems have recently been published. 15, 20-22 Measurement of wrist rigidity simulates the commonest clinical manoeuvre, and is easily accessible to testing while the subject is sitting. Webster and his co-workers $9,11-13$ and Potvin and Tourtelotte ${ }^{15}$, 22 who improved and clinically validated objective methods, had previously studied rigidity by moving the patient's arm about the elbow joint. We found that the measurements employed to study movement about the elbow were not suitable for optimal evaluation of rigidity about the wrist. Therefore, we employed a torque motor to move the wrist passively to explore the range of angular velocities and displacements to determine suitable indices for detecting rigidity.

\section{Patients and Methods}

A torque motor with position feedback was employed to oscillate the hand over a range of angular velocities from 12 to 240 degrees per second and over angular displacements from \pm 15 to \pm 30 degrees. The position signal was generated by a frequency generator and was fed to a Kepco operational power supply (BDP15-20). The amplified position signal in turn drove an Aeroflex TQ64 brushless DC torque motor with a custom made position feedback circuit. Peak torque of the motor was $6.21 \mathrm{~nm}$, and mechanical stoppers were placed at $\pm 70^{\circ}$, providing protection against excessive handle movement. The DC motor was vertically mounted with the shaft directly driving the handle above, so that it produced a horizontal movement of the hand support that was attached (Figure 1). The patient's hand was placed on the support such that the shaft of the torque motor was immediately below the wrist joint moving the wrist

From the Department of Medicine, Division of Neurology, University Hospital, U.B.C. Site.

Received August 2, 1988. Accepted November 28, 1988

*Present address is Department of Neurology, University of Helsinki, HYKS, Haartmaninkatu 4, 00290 Helsinki, Finland

Reprint requests to: Dr. Donald B.Calne, Department of Medicine, Division of Neurology, Rm S129, ACU, University Hospital, 2211 Wesbrook Mall, Vancouver, British Columbia, Canada V6T IW5. 
into extension and flexion. The hand holder could be tightened by adjustable rubber cushions to limit free movement within the apparatus. The patient sat during the experiments. A total of eleven movement frequencies (from 0.2 to $2.0 \mathrm{~Hz}$ ) each at four different amplitudes (15, 20, 25, 30 degrees) were employed after preliminary studies using both slower and faster frequencies. Sinusoidal and linear movements were investigated in the preliminary analysis.

The method described by Mortimer and Webster9, 12-13 was employed to compute the area inside a hysteresis torque loop, which is equivalent to the work done for one complete cycle. The mean value of five separate measurements was calculated at each amplitude and frequency. The objective rigidity score (ORS) was expressed in Newton-meter-degrees. The result of one such series of measurements is illustrated in Figure 2. The patient was instructed to relax and to avoid resisting or assisting the movement produced by the torque motor. Measurement commenced after the subject had become accustomed to the recording situation. This ORS at rest was compared with the clinical score for rigidity (CRS) at the wrist $(0=$ no rigidity; 1 =rigidity observed only during contralateral activation; $2=$ mild to moderate rigidity at rest; $3=$ very rigid), which was performed immediately before the objective measurement. Contralateral motor activation was achieved by instructing the subject to make a fist repeatedly with the free hand at a frequency of about $0.5 \mathrm{~Hz}$. The ORS obtained during contralateral activation was referred to as "activated rigidity".

Preliminary analysis of ORS using both linear and sinusoidal movements indicated that the score was about $12 \%$ higher with linear (ramp) movements than with sinusoidal movements. The latter were, however, more comfortable to test subjects especially at faster movement frequencies, since there were less abrupt changes in the direction of movement. In addition, the subjects' tendency to involuntarily assist the movement produced by the torque motor was less during sinusoidal than linear displacement. For these reasons, we employed sinusoidal movements in the final analysis of the amplitude/velocity relationship of parkinsonian rigidity.

Twenty-nine patients with Parkinson's disease (age 39-78 years, mean 59) and 12 normal subjects (age 29-65 years, mean 46) were studied. The patients were treated with a variety of antiparkinsonian drugs including levodopa. Many of them experienced fluctuations of disability which allowed "within patient" comparison at different clinical rigidity values. In 5 of the 29 patients the speed of fluctuation of the clinical disability was slow enough for complete analysis of all velocity amplitudes relationships without significant changes in the CRS during the experiment. Student's t-test and correlation analysis were employed in the statistical evaluation of the results.

\section{RESULTS}

The mean ORS in normal subjects rose approximately linearly with increasing amplitude from \pm 15 to \pm 30 degrees (figure 3 ) and speed of movement from 24 to 190 degrees/second $(0.2$ to $1.6 \mathrm{~Hz}$ at $\pm 30^{\circ}$, sinusoidal) (figure 4 ). ORS in patients with Parkinson's disease were highest with velocities between 140 and $190 \mathrm{degrees} / \mathrm{second}\left(1.2\right.$ to $1.6 \mathrm{~Hz}$ at $\pm 30^{\circ}$ ), decreasing thereafter in contrast to the slight increase in the normal subjects at higher speeds (figure 4). Slow movement velocities (less than 70 degrees/second, or $0.6 \mathrm{~Hz}$ at $\pm 30^{\circ}$ ) were less sensitive in discriminating abnormal muscle tone, and had the additional disadvantage that the subjects sometimes assisted the movement. This was reflected as occurrence of negative ORS, particularly

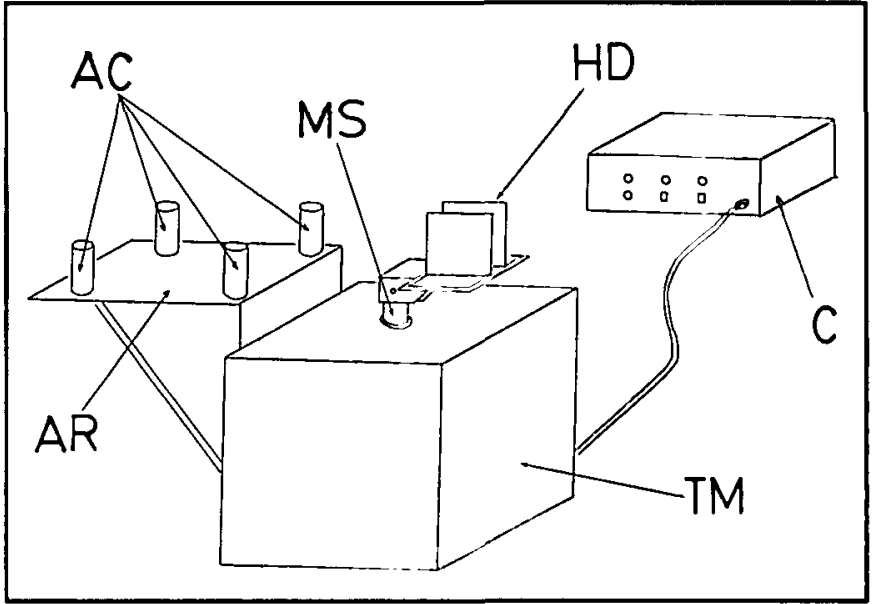

Figure I - Diagram of apparatus for measuring objective rigidity scores. $(A C=$ adjustable rubber cushions, $A R=$ arm rest, $M S=$ motor shaft, $H D=$ handle $C=$ controller,$T M=$ torque motor inside aluminium case).

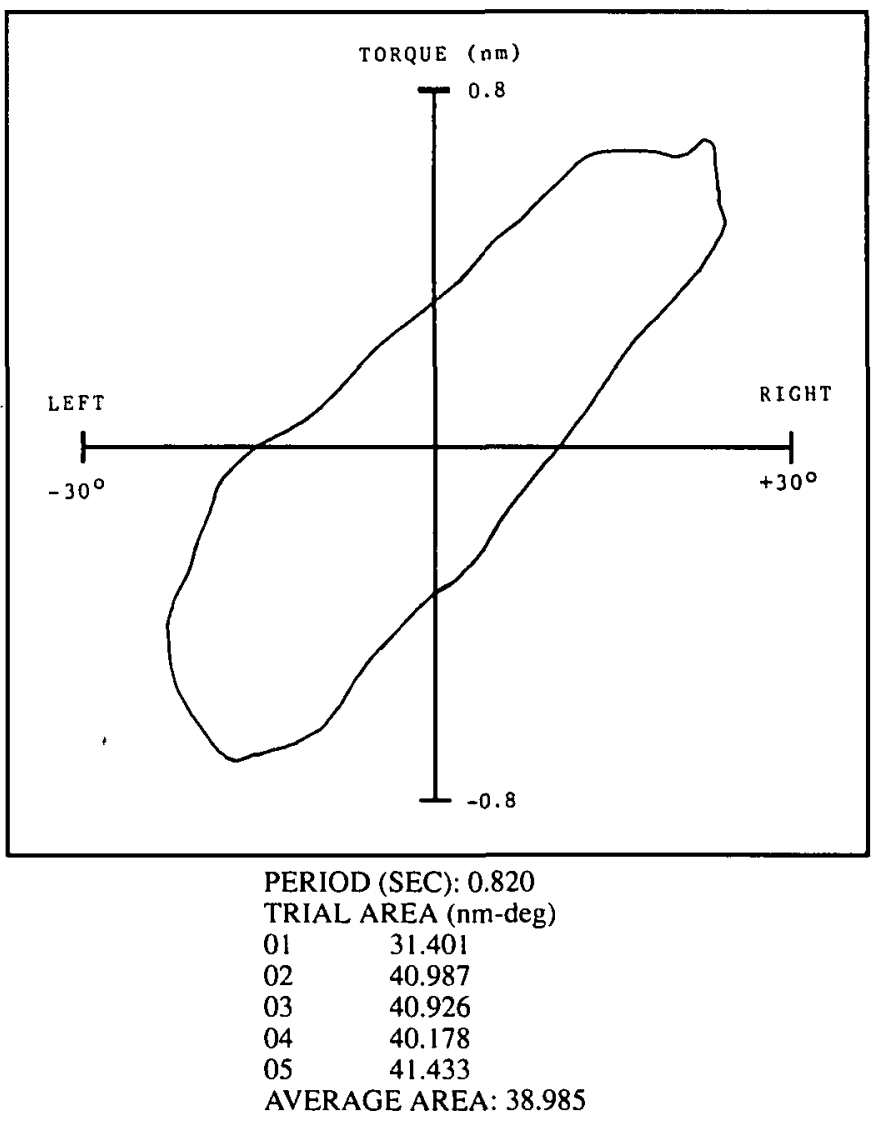

Figure 2 - Illustration of recording of wrist rigidity in a patient with Parkinson's disease employing the measurement of hysteresis for $\pm 25^{\circ}$ movement of the wrist. The area within the loop represents the mean amount of work done, equivalent to energy loss ( $\mathrm{nm}-\mathrm{deg}$ ), in five individual trails. The CRS of the patient (age 65 years) was 3 . 
in subjects with low CRS of 0 to 1 . This tendency for voluntary movement to intercede decreased with increasing movement speed and was only rarely seen at velocities equivalent to over 1 $\mathrm{Hz}$.

Table 1 shows correlation between the clinical rigidity score and the objective rigidity, employing wrist oscillation at 1.0 to $1.8 \mathrm{~Hz}$. The correlation was generally better at higher movement amplitudes and velocities.

With sinusoidal velocities between 140 and 190 degrees/second and amplitudes between \pm 25 and \pm 30 degrees, a mean ORS of $6.1 \mathrm{~nm}-\mathrm{deg}$ (resting) and $7.2 \mathrm{~nm}-\mathrm{deg}$ (activated) was obtained for normal subjects aged over 45 years $(\mathrm{N}=7$, mean age 53 years). The 29 patients with Parkinson's disease were divided into four groups based on the clinical score $(0,1,2$, and 3). The ORS was comparable to that observed in the normal subjects in patients with a CRS of zero (figure 5). Above zero, the ORS was augmented by contralateral activation, and increased $(p<0.01)$ appropriately for clinical scores of 2 and 3 (figure 5). Evaluation of patients who fluctuated in relation to drug treatment indicated that the objective score clearly discriminated "on" and "off" phases (figure 6) in individual cases.

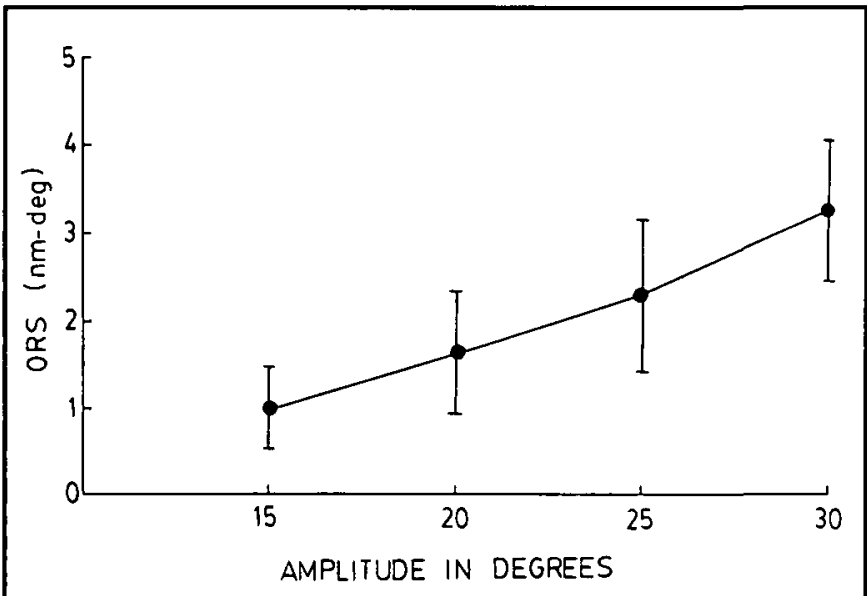

Figure 3-Mean ORS (work in $\mathrm{nm}$-deg) at movement amplitudes from $\pm 15^{\circ}$ to $\pm 30^{\circ}$, constant velocity $(140 \mathrm{deg} / \mathrm{sec})$. The score obtained was higher at larger amplitudes. $N=4$.

Table 1: Correlation Coefficients Between ORS and CRS at Different Movement Amplitudes and Frequencies in 18 Patients with Parkinson's Disease. (p Values in Bracklets)

\begin{tabular}{lllll}
\hline \hline Frequency (Hz) & $\mathbf{4}$ & \multicolumn{3}{c}{ Movement amplitude } \\
$\mathbf{\pm 2 5 ^ { \circ }}$ & $\mathbf{\pm 2 5 ^ { \circ }}$ & $\mathbf{\pm 3 0 ^ { \circ }}$ \\
\hline \multirow{2}{*}{1.0} & .56 & .58 & .62 & .67 \\
& $(.0132)$ & $(.0110)$ & $(.0053)$ & $(.0018)$ \\
1.2 & .58 & .65 & .65 & .72 \\
& $(.0097)$ & $(.0025)$ & $(.0027)$ & $(.0005)$ \\
1.4 & .68 & .72 & .73 & .74 \\
& $(.0015)$ & $(.0004)$ & $(.0004)$ & $(.0002)$ \\
1.6 & .66 & .75 & .74 & .84 \\
& $(.0021)$ & $(.0001)$ & $(.0002)$ & $(.0000)$ \\
1.8 & .75 & .75 & .73 & .82 \\
& $(.0002)$ & $(.0002)$ & $(.0003)$ & $(.0000)$
\end{tabular}

\section{DisCUSSION}

The increasing interest in new drugs for the treatment of Parkinson's disease justifies objective tests for the measurement of clinical signs. The optimal test is one which is easy, quick, and yields consistent results. The rigidity test described here meets these criteria. Bilateral wrist rigidity can be measured in less than two minutes. Our experience indicates good correlation with the clinical assessment. It is quite clear that these objective tests cannot replace clinical scoring systems ${ }^{15}, 20-22$ which are faster, cheaper, and more flexible by allowing rigidity assessment about several joints. They rather supplement the clinical scores and have the advantage of providing an unbiased and more finely graded measure which is unaffected by changes in the examiner over the period of study. This last asset may become increasingly important in studies evaluating long-term changes and disease progression over several years.

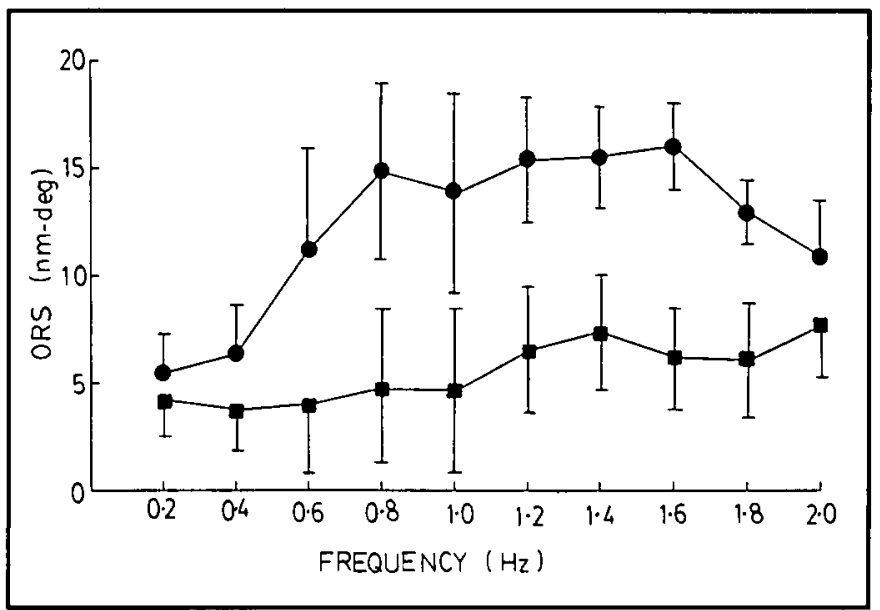

Figure 4-Mean ORS of 8 patients with Parkinson's disease (CRS 2 to 3, mean 2.4) and 5 elderly controls. Frequencies (sinusoidal) 0.1 $2.5 \mathrm{~Hz}$, amplitude $\pm 30^{\circ}$. The ORS was highest between frequencies 1.2 and $1.6 \mathrm{~Hz}(140-190 \mathrm{deg} / \mathrm{sec}) .(\boldsymbol{O}=8$ patients, $\boldsymbol{\Delta}=5$ controls $)$.

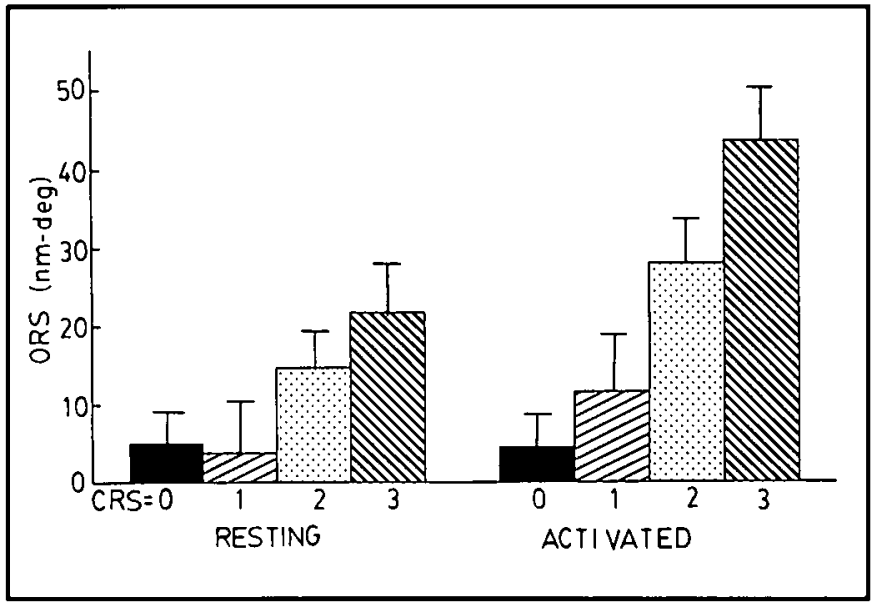

Figure 5 - ORS of 29 patients with Parkinson's disease, some with clinical fluctuations measured more than once. The ORS were divided into four groups based on their CRS $(0,1,2$, and 3 , and $N=12$, 15,13 , and 10 respectively). Both the ORS resting and ORS activated are illustrated. Amplitudes $\pm 25^{\circ}$ at $1.4 \mathrm{~Hz}$. 


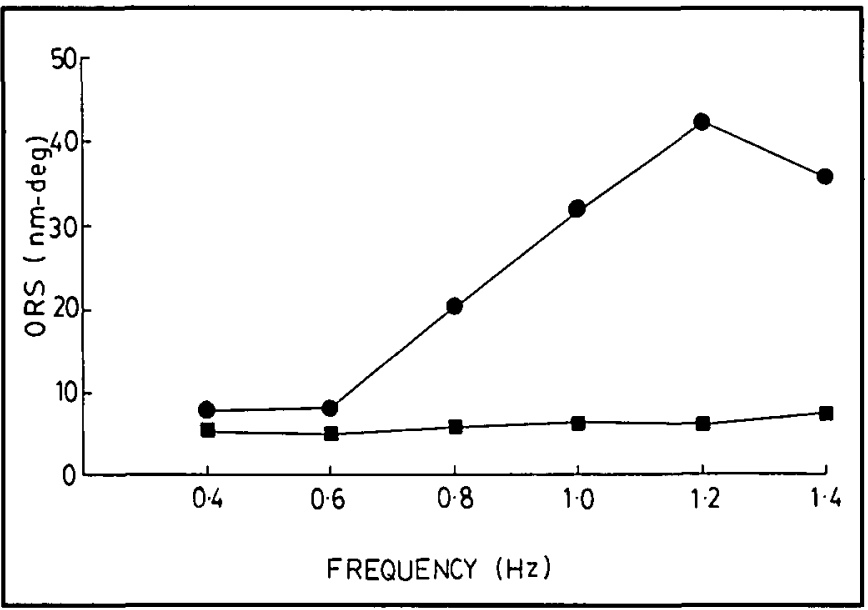

Figure 6 -ORS (nm-deg) for different amplitudes of movement of the wrist obtained from a male 55-year-old patient with Parkinson's disease who experienced marked fluctuations in clinical disability in relation to drug treatment. The two series of measurements were made when he was rigid. ( $C R S=3)$ and when he was slightly dyskinetic ( $\boldsymbol{D} C R S=0)$.

Rigidity about the wrist joint has not, to our knowledge, undergone previous objective evaluation in parkinsonism. Tsementis et al. ${ }^{19}$ evaluated two methods for testing muscle tone in patients with decerebrate rigidity. They employed either a square wave force and calculated the compliance as an index of spasticity, or a sinusoidal force and used the resonant frequency of the joint as an index of spasticity. The latter proved to be more reliable and reproducible. Their results cannot be compared with ours, not only because the patients suffered from different diseases, but also because we used position feedback to obtain predetermined movement amplitude whereas Tsementis et al. ${ }^{19}$ employed force feedback and allowed changes in amplitude.

Webster and his co-workers9, 11.13 and Potvin, Tourtelotte and associates 15,22 have previously measured rigidity about the elbow joint using methods of evaluation that are conceptually similar to ours. They limited the angular movement speed to $10-$ 40 degrees/second whereas we moved the wrist up to 240 degrees/second. This is because of the fact that it is possible to oscillate the wrist at higher frequencies than the elbow, and the mass to be moved is significantly smaller at the wrist so that torque motors with limited force output are able to satisfy the power requirements.

We observed that movement speeds between 140 and 190 degrees/second gave the most reliable and reproducible rigidity values with good correlation to the CRS. This faster movement speed also differentiated the abnormality better than the slower speeds (see figures 5 and 6) and the problem of voluntary assistance by the patients was eliminated. Neither of these observations are new. Webster"l pointed out the tendency for the subjects to subconsciously drive the turntable. Potvin and Tourtelotte 15 noted that "rigidity was more pronounced at higher velocities for patients than for normal subjects".

Though $\pm 30^{\circ}$ may be problematic in those rare cases with severe rigidity which has a tendency to limit the range of movement, we have adopted a routine of $\pm 30^{\circ}$ at $1.6 \mathrm{~Hz}$ for the study of both resting and activated rigidity. With these indices there is a good correlation with CRS. Finally it may be useful for the clinician to bear in mind the optimal velocity and amplitude of wrist movement for testing parkinsonian rigidity.

\section{ACKNOWLEDGEMENT}

This work was supported by the Dystonia Medical Research Foundation and the Medical Research Council of Canada.

\section{REFERENCES}

1. Wright V, Johns RJ. Physical factors concerned with the stiffness of normal and diseased joints. Bull Johns Hopk Hosp 1960; 106: 215-231.

2. Johns RJ, Wright V. Relative importance of various tissues in joint stiffness. J Applied Physiol 1962; 17: 824-828.

3. Long C, Thomas D, Crochetiere WJ. Objective measurement of muscle tone in the hand. Clin Pharmacol Ther 1964; 5: 909-917.

4. Bäcklund I, Tiselius P. Objective measurement of joint stiffness in rheumatoid arthritis. Acta Rheum Scand 1967; 137: 275-288.

5. McKinley JC, Berkwitz NJ. Quantitative studies on human muscle tonus. Arch Neurol Psychiatry (Chicago) 1928; 19: 1036-1056.

6. Schaltenbrand G. Muscle tone in man. Arch Surg 1929; 18: 19741885.

7. La Joie WJ, Gersten JW. An objective method of evaluating muscle tightness: preliminary observations on the effectiveness of various procedures in producing muscle relaxation in hemiplegic extremity. Arch Phys Med 1952; 33: 595-603.

8. Agate FJ, Doshay LJ, Curtis FK. Quantitative measurement of therapy in paralysis agitans. JAMA 1956; 160: 352-354.

9. Webster DD. A method of measuring the dynamic characteristics of muscle rigidity, strength, and tremor in the upper extremity. I.R.E. Trans Med Electron ME-6 1959; 6: 159-164.

10. Boshes B, Wachs H, Brumlik J, et al. Studies of tone, tremor, and speech in normal persons and parkinsonian patients. Neurology 1960; 10: 805-813.

11. Webster DD. Dynamic measurement of rigidity, strength, and tremor in Parkinson patients before and after destruction of mesial globus pallidus. Neurology 1960; 10: 157-163.

12. Webster DD. Rigidity in extrapyramidal disease. J. Neurosurg 1966; 24 (Suppl II): 299-309.

13. Webster DD, Mortimer JA. Failure of L-dopa to relieve activated rigidity in Parkinson's disease. In: Messiha FS, Kenny AD (eds.). Parkinson's disease: neurophysiological, clinical and related aspects. Plenum, New York, 1977; 297-313.

14. Halpern D, Patterson R, Mackie R, et al. Muscular hypertonia: quantitative analysis. Arch Phys Med Rehabil 1979; 60: 208. 218.

15. Potvin AR, Tourtelotte WW (eds.). Quantitative examination of neurologic functions. Vol II: methodology for test and patient assessments and design of a computer-automated system. CRC Press: Boca Raton, Florida 1985.

16. Rushworth G. Spasticity and rigidity: an experimental study and review. J Neurol Neurosurg Psychiatry 1960; 23: 99-118.

17. Leavitt LA, Beasley WC. Clinical application of quantitative methods in the study of spasticity. Clin Pharmacol Ther 1964; 5: 918 941.

18. Timberlake WH. Evaluation of hypertonia with the use of a gravity-driven ergograph. Clin Pharm Ther 1964; 5: 879-882.

19. Tsementis SA, Gillingham FJ, Gordon A, et al. Two methods of measuring muscle tone applied in patients with decerebrate rigidity. J. Neurol Neurosurg Psychiatry 1980; 43: 25-36.

20. Teräväinen H, Calne $\mathrm{D}$. Quantitative assessment of parkinsonian deficits. In: Rinne UK, Klinger M, Stamm G (eds.). Parkinson's disease - current progress, problems and management. Elsevier, Amsterdam, 1980; 145-164.

21. Marsden CD, Schachter M. Assessment of extrapyramidal disorders. In: Lader MH, Richens A (eds.). Methods in clinical pharmacology - central nervous system. London: Macmillan, 1981; 89-111.

22. Potvin AR, Tourtelotte WW (eds.). Quantitative examination of neurologic functions. Vol l: Scientific basis and design of instrumented tests. CRS Press: Boca Raton, Florida, 1985. 